\title{
Impact of zinc oxide, benzoic acid and probiotics on the performance and cecal microbiota of piglets
}

\author{
Caio Abercio da Silva ${ }^{1 *}$, Leonardo Aparecido Teixeira Bentin ${ }^{2,3}$, Cleandro Pazinato Dias 4 , \\ Marco Aurélio Callegari ${ }^{4}$, Vitor Barbosa Facina ${ }^{5}$, Francine Taniguchi Falleiros Dias ${ }^{5}$, Adsos Passos ${ }^{5}$, \\ Cláudia Cassimira da Silva Martins ${ }^{5}$ and Marcio Carvalho Costa $^{3}$ (D)
}

\begin{abstract}
Background: Intestinal health remains a key factor in animal production because it is essential for digestion, absorption and bacterial fermentation. Feed additives have been used to attenuate the weaning stress such as Zinc Oxide ( $\mathrm{ZnO})$ and benzoic acid $\left(\mathrm{C}_{7} \mathrm{H}_{6} \mathrm{O}_{2}\right)$. The objective of this study was to evaluate the impact of of benzoic acid and probiotics (BA + P) on performance, diarrhea and cecal microbiota of piglets in the nursery phase (23 to 65 days).

Results: One hundred and sixty weaned piglets with an initial weight of $6.335 \pm 0.698 \mathrm{~kg}$ and 23 days of age were submitted to four treatments: supplementation with 2500 ppm of Zinc oxide (ZnO), supplementation with a commercial blend of benzoic acid and probiotics (Bacillus licheniformis, Bacillus subtilis and Enterococcus faecium NCIMB 10415; Vevogut $\left.\mathrm{P}^{\circledR}\right)(B A+P)$, supplementation with Zinc oxide plus benzoic acid and probiotics $(Z n O+B A+P)$, and controls receiving only the basal diet without any supplementation. At 65 days of age, 32 piglets ( $n=8$ per treatment) were slaughtered for the evaluation of the cecal microbiota. Supplementation with $\mathrm{ZnO}$ and BA $+\mathrm{P}$ were associated with better feed conversion $(P<0.05)$ in the early stage ( 23 to 49 days) and with an improvement in all performance parameters over the entire experimental period. The occurrence of diarrhea was lower $(P<0.05)$ in the BA + P group. The 4 most abundant phyla along with unclassified bacteria represented $93 \%$ of all sequences. Firmicutes dominated the cecal microbiota of all groups, followed by Bacteroidetes. Richness represented by the observed number of genera and by the Chao index were statistically lower in $\mathrm{ZnO}$ and $\mathrm{ZnO}+\mathrm{BA}+\mathrm{P}$ supplemented animals compared to controls. The beta diversity analysis that compares similarities between bacterial communities demonstrated formation of two distinct clusters containing samples with and without supplementation with $\mathrm{ZnO}$, confirming a strong influence of $\mathrm{ZnO}$ on the intestinal microbiota.
\end{abstract}

Conclusion: The use of Benzoic acid with probiotics yields similar performance results with lower impact on the gut microbiota compared to $\mathrm{ZnO}$, and it should be considered as a potential alternative in swine production.

Keywords: Antibiotics, Diarrhea, Organic acids, Swine

*Correspondence: casilva@uel.br

1 Department of Animal Science, Universidade Estadual de Londrina, Londrina, Paraná, Brazil

Full list of author information is available at the end of the article

\section{Backgound}

Intestinal health remains a key factor in animal production because it is essential for adequate food digestion, nutrients absorption and energy production by bacterial fermentation. Furthermore, it is the place of action where pathogens cause concerning diseases in swine original author(s) and the source, provide a link to the Creative Commons licence, and indicate if changes were made. The images or other third party material in this article are included in the article's Creative Commons licence, unless indicated otherwise in a credit line to the material. If material is not included in the article's Creative Commons licence and your intended use is not permitted by statutory regulation or exceeds the permitted use, you will need to obtain permission directly from the copyright holder. To view a copy of this licence, visit http://creativecommons.org/licenses/by/4.0/. 
production. During the first weeks of life, the gastro intestinal tract passes through several adaptation processes that may have an impact on animal performance [1-3] Weaning is the most critical phase in swine production and post-weaning diarrhea remains the most common cause of morbidity and mortality in swine herds resulting in great economical losses [4-6].

Several strategies to attenuate the negative impact of the stress observed during weaning have been evaluated $[7,8]$. Feed additives, such as Zinc Oxide ( $\mathrm{ZnO})[9]$ and benzoic acid $\left(\mathrm{C}_{7} \mathrm{H}_{6} \mathrm{O}_{2}\right)$ [7] are globally used in swine production systems. The use of those products is associated with lower incidence of diarrhea and greater weight gain during weaning $[10,11]$. Zinc is essential for the intestinal mucosa integrity and protects against pathogenic organisms by modulation of the immune system [12], but the excessive use of $\mathrm{ZnO}$ during the last decade as an alternative for antibiotic growth promoters has been associated with the development of bacterial resistance to this product [13] and with environmental pollution [14]. Therefore, alternatives to this product such as essential oils and probiotics deserve further investigation.

The importance of the intestinal microbiota, especially of bacteria, has been revised after the development of next generation DNA sequencing (NGS) technologies, which are much more comprehensive than traditional culture-based approaches. Several studies have used NGS to reveal that the swine intestinal tract harbours a complex bacterial community that can vary according to age, diet and management [15]. The intestinal microbiota has been shown to be essential for the maintenance of intestinal health and to play a major role in the development of the local and systemic immune system. Therefore, microbiota manipulation has been attempted with the objective of improving health [16]. Amongst the different strategies to modulate the intestinal microbiota, the use of probiotics is a viable option to be used in swine production [17-19].

Dietary supplementation with $\mathrm{ZnO}$ affects the intestinal microbiota of pigs $[13,20]$, but studies comparing the impact of different products in a controlled environment remain to be performed. This study aimed to investigate the impact of $\mathrm{ZnO}$, benzoic acid and probiotics on growth performance, control of diarrhea and cecal microbiota composition of piglets at the nursery phase.

\section{Material and methods \\ Study design}

One hundred and sixty weaned piglets (Camborough PIC x AG 337 sires) at 21 days of age were raised in an experimental unit (Akei Animal Research, Fartura, São Paulo, Brazil), according to a random design of four experimental groups: supplementation with $2500 \mathrm{ppm}$ of
Zinc Oxide $(\mathrm{ZnO})$, supplementation with $0.4 \%$ of a commercial blend of benzoic acid and probiotics (Bacillus licheniformis, Bacillus subtilis and Enterococcus faecium NCIMB 10415; Vevogut $P^{\circledR}$, DSM Animal Nutrition) $(\mathrm{BA}+\mathrm{P})$, supplementation with Zinc oxide plus benzoic acid and probiotic $(\mathrm{ZnO}+\mathrm{BA}+\mathrm{P})$, and controls receiving only the basal diet without supplementation.

Piglets were housed in 2,55 $\mathrm{m}^{2}$ pens ( 2 females or 2 males per pen) with controlled temperature. Therefore, each experimental group contained 40 animals (20 males and 20 females) housed in 10 different pens.

Additional file 1: Tables S1 and S2 specify the composition of diet used at the different growing phases: Pre starter I ( 21 to 28 days), pre-starter II ( 29 to 35 days), starter I (35 to 49 days) and starter II (49 to 63 days). Basal diet consisted of corn and soybean meal, with water and mashed ration offered ad libitum.

\section{Performance}

Piglets were weighed individually on day 0 (23 days of age), 5 (28 days of age), 12 ( 35 days of age), 26 (49 days of age) and 40 (63 days of age) of the trial to calculate average daily gain (ADG) for each period and considering all phases. Daily feed intake was determined by pen, and mortality was recorded to adjust the feed conversion ratio.

Fecal consistency was evaluated daily and classified as normal (score 0 ), soft (score 1), loose (score 2), or diarrhea (score 3) [21]. A diarrhea index expressed in percentage was calculated as $100 \times$ number of piglets that had diarrhea/total number of piglets [22].

Thirty-two piglets (8 per treatment, being four barrows and four females, randomly chosen) were slaughtered at 65 days of life and cecal content was aseptically collected and immediately refrigerated for transportation and frozen at $-80^{\circ} \mathrm{C}$ until DNA extraction. DNA was extracted using a commercial kit DNeasy PowerSoil (QIAGEN, Hilden, Germany) and the V4 region of the 16S rRNA gene amplified using the primers 515F: GTGCCA GCMGCCGCGGTAA and 806R: GGACTACHVGGG TWTCTAAT. Amplicons were then sequenced with a MiSeq Illumina sequencer (Illumina, Inc., San Diego, CA, USA) single end sequencing using a V3 kit for $300 \mathrm{bp}$ reaction.

Bioinformatic analysis was carried out using the software mothur [23], following the protocol suggested by Kozich et al. (2013) [24]. Reads containing more than $300 \mathrm{bp}$ or more than 8 homopolimers were excluded. Good quality reads were aligned to the SILVA reference alignment and classified according to the Ribosomal Database Project [25], 2016 release. Chimeras were removed with the vsearch algorithm. Reads classified as Chloroplast, mitochondria, Archaea or eukaryota were 
removed from the analysis. The phylotype approach was used by grouping all reads belonging to the same genus (94\% similarity). Subsampling using the smallest number of reads obtained in a sample was used to standardize non-uniform samples in an attempt to avoid introducing bias into the analysis. The software mothur was also used to calculate richness by the total number of observed genera and by the Chao index. Diversity was estimated by the Simpson's index. Community membership, which takes into account each genus present in a community, was calculated by the Jaccard index, and community structure, which takes into account each genus and their relative abundances, was calculated by the Yue and Clayton index. The distance matrices created for both, membership and structure were subsequently used to generate dendrograms and Principal Coordinate Analysis (PCoA) graphs for visualisation of similarity between samples.

\section{Statistical analysis}

Body weight, ADG, DFI and FRC were submitted to analysis of variance (ANOVA) and means were compared by Tukey's test. The mean of the diarrhea index was compared between groups by the chi-squared test. Richness and diversity indices were compared between groups using an ANOVA test with Bonferroni correction for multiple comparisons using GraphPad Prism 7.0a (GraphPad Software Inc., California, USA), considering $P$ values $<0.05$ as significant. Relative abundances were compared by Tukey's test.

Beta diversity (Jaccard and Yue and Clayton indices) were compared using the analysis of molecular variance (AMOVA) test. Linear Discriminant Analysis Effective Size (LEfSe) was used to find bacterial taxa significantly associated to each treatment [26].

\section{Results}

\section{Performance}

Animals supplemented with Benzoic acid plus probiotic and $\mathrm{ZnO}+$ Benzoic acid plus probiotic had significantly better FCR than the control group during the Pre-Starter I phase. Those groups, along with $\mathrm{ZnO}$ supplemented animals also performed better compared to controls during the Starter I phase I (Table 1). Final weight at Starter II was significantly higher in Benzoic acid plus probiotic likely because they started this phase heavier due to better performance at Starter I, as there was no statistical difference in ADG (despite a numerically greater average in that group). Overall, $\mathrm{ZnO}$ and Benzoic acid plus probiotic treatments significantly improved daily feed intake (DFI) and average daily gain (ADG) compared to controls.

The diarrhea ocurrence (number of piglets that had diarrhea) and the diarrhea index $(100 \times$ number of piglets that had diarrhea/total number of piglets) are presented in Table 2. Results of statistical analysis showed that controls presented higher frequency of severe diarrhea (score 3) and of intermediary and severe diarrhea together (score $2+3$ ), suggesting that supplementation with $\mathrm{ZnO}$ and/or Benzoic acid plus probiotic was associated with lower incidence of diarrhea. No deaths were recorded during the study period.

\section{Microbiota analysis}

A total of 2,432,186 good quality sequences were retained for the final analysis, with an average of 76,006 reads per sample (SD 7048). A subsample using the smallest number of reads obtained in a sample (1310 reads) was used to standardize non-uniform samples in an attempt to avoid introducing bias into the analysis. This approach yielded $99.21 \%$ (SD, $0.15 \%$ ) coverage indicating that most of the genera present in the samples were adequately detected.

Figure 1A represents the overall relative abundance of the main phyla ( $>1 \%$ abundance) found in the swine cecum. The 4 most abundant phyla along with unclassified bacteria represented $93 \%$ of all sequences. Firmicutes dominated the cecal microbiota of all groups, followed by Bacteroidetes. Figure 1B represents the relative abundances of the main genera found in the cecum of pigs supplemented with $\mathrm{ZnO}$ and/or Benzoic acid plus probiotic. The most abundant taxa were Roseburia, Prevotella, Gemmiger, and Streptococcus spp. Although some visual differences between treatments can be observed from Fig. 1B, there were no statistical differences found at the phylum or genus levels. The Linear Discriminant Analysis Effective Size (LefSe) analysis also failed to identify bacterial taxa associated to each of the specific treatments.

Results of the statistical analysis comparing richness and diversity indices between experimental groups are shown in Table 3 and Fig. 2. Richness represented by the observed number of genera and by the Chao index were statistically lower in $\mathrm{ZnO}$ and $\mathrm{ZnO}+$ Benzoic acid plus probiotic supplemented animals compared to controls, suggesting a strong influence of $\mathrm{ZnO}$ on the number of different bacteria comprising the cecal microbiota. Results also show that supplementation had no influence on bacterial diversity of studied animals addressed by the Simpson's index.

The beta diversity analysis that compares similarities between bacterial communities is represented by the Principal Coordinate Analysis (PCoA) (Fig. 3). This analysis demonstrated formation of two distinct clusters containing samples with and without supplementation with $\mathrm{ZnO}$. Those differences were even more evident in communities' membership (Fig. 3B) confirming that $\mathrm{ZnO}$ changes the overall microbiota composition, affecting 
Table 1 Mean values of live weight, daily feed intake (DFI), average daily gain (ADG) and feed conversion rate (FCR) of weaning piglets supplemented with Zinc Oxide ( $\mathrm{ZnO})$, Benzoic acid plus probiotic (BA+P) and $\mathrm{ZnO}+\mathrm{BA}+\mathrm{P}$ according the phases

\begin{tabular}{|c|c|c|c|c|c|c|}
\hline \multirow[t]{2}{*}{ Phases } & \multicolumn{4}{|c|}{ Treatment } & \multirow[t]{2}{*}{ CV \% } & \multirow[t]{2}{*}{$p$-value } \\
\hline & Control & $\mathrm{ZnO}$ & Benzoic acid + Probiotic & $\begin{array}{l}\mathrm{ZnO}+\text { Benzoic } \\
\text { acid + Probiotic }\end{array}$ & & \\
\hline \multicolumn{7}{|c|}{ Pre starter I (23-28d) } \\
\hline Initial weight, kg & 6.343 & 6.331 & 6.330 & 6.357 & 1.20 & 0.835 \\
\hline DFI, kg & 0.212 & 0.223 & 0.228 & 0.221 & 25.61 & 0.932 \\
\hline $\mathrm{ADG}, \mathrm{kg}$ & 0.135 & 0.153 & 0.162 & 0.170 & 28.76 & 0.351 \\
\hline FCR & $1.672^{b}$ & $1.479^{\mathrm{ab}}$ & $1.419^{\mathrm{a}}$ & $1.418^{\mathrm{a}}$ & 12.87 & 0.017 \\
\hline Final weight, kg & 7.290 & 7.406 & 7.465 & 7.403 & 5.81 & 0.831 \\
\hline \multicolumn{7}{|c|}{ Pre starter II (28-35d) } \\
\hline DFI, kg & 0.410 & 0.454 & 0.465 & 0.430 & 13.36 & 0.183 \\
\hline $\mathrm{ADG}, \mathrm{kg}$ & 0.311 & 0.359 & 0.370 & 0.337 & 16.73 & 0.126 \\
\hline FCR & 1.380 & 1.280 & 1.265 & 1.270 & 14.35 & 0.470 \\
\hline Final weight, kg & 9.156 & 9.561 & 9.686 & 9.428 & 6.03 & 0.213 \\
\hline \multicolumn{7}{|l|}{ Starter I (35-49d) } \\
\hline DFl, kg & $0.508^{b}$ & $0.565^{\mathrm{ab}}$ & $0.606^{\mathrm{a}}$ & $0.550^{\mathrm{ab}}$ & 9.99 & 0.004 \\
\hline $\mathrm{ADG}, \mathrm{kg}$ & $0.281^{b}$ & $0.369^{a}$ & $0.373^{a}$ & $0.367^{\mathrm{a}}$ & 12.34 & $<0.001$ \\
\hline FCR & $1.834^{b}$ & $1.540^{\mathrm{a}}$ & $1.640^{\mathrm{a}}$ & $1.498^{\mathrm{a}}$ & 10.98 & $<0.001$ \\
\hline Final weight, kg & $11.968^{b}$ & $13.253^{\mathrm{a}}$ & $13.421^{\mathrm{a}}$ & $13.100^{\mathrm{a}}$ & 6.02 & $<0.001$ \\
\hline \multicolumn{7}{|l|}{ Starter II (49-63d) } \\
\hline DFI, kg & 0.983 & 1.042 & 1.063 & 1.037 & 7.69 & 0.158 \\
\hline $\mathrm{ADG}, \mathrm{kg}$ & 0.557 & 0.556 & 0.588 & 0.549 & 9.17 & 0.347 \\
\hline FCR & 1.780 & 1.874 & 1.808 & 1.900 & 7.22 & 0.184 \\
\hline Final weight, kg & $21.035^{b}$ & $22.150^{\mathrm{ab}}$ & $22.841^{\mathrm{a}}$ & $21.935^{\mathrm{ab}}$ & 5.33 & 0.015 \\
\hline \multicolumn{7}{|l|}{ Total (23-63d) } \\
\hline $\mathrm{DFI}, \mathrm{kg}$ & $0.635^{b}$ & $0.682^{\mathrm{a}}$ & $0.704^{a}$ & $0.671^{\mathrm{ab}}$ & 6.18 & 0.007 \\
\hline ADG, kg & $0.373^{b}$ & $0.405^{\mathrm{a}}$ & $0.423^{\mathrm{a}}$ & $0.397^{a b}$ & 7.44 & 0.006 \\
\hline FCR & 1.711 & 1.683 & 1.664 & 1.681 & 5.31 & 0.703 \\
\hline
\end{tabular}

${ }^{a, b}$ Means with different letters correspond to significance by Tukey's Test $(P<0.05)$

Table 2 Mean values of diarrhea occurrence and index observed in post-weaning piglets supplemented with Zinc Oxide $(\mathrm{ZnO})$, Benzoic acid plus probiotic $(\mathrm{BA}+\mathrm{P})$ and $\mathrm{ZnO}+\mathrm{BA}+\mathrm{P}$

\begin{tabular}{lllll}
\hline Parameters & $\begin{array}{l}\text { Treatment } \\
\text { Control }\end{array}$ & ZnO & $\mathbf{B A}+\mathbf{P}$ & $\mathbf{Z n O}+\mathbf{B A}+\mathbf{P}$ \\
\hline Diarrhea occurrence & & & & \\
Score 2 & $11^{\mathrm{b}}$ & $1^{\mathrm{a}}$ & $4^{\mathrm{ab}}$ & $3^{\mathrm{ab}}$ \\
Score 3 & $38^{\mathrm{c}}$ & $21^{\mathrm{b}}$ & $18^{\mathrm{ab}}$ & $8^{\mathrm{a}}$ \\
Score 2+3 & $49^{\mathrm{b}}$ & $22^{\mathrm{a}}$ & $22^{\mathrm{a}}$ & $11^{\mathrm{a}}$ \\
Diarrhea index, \% & & & & \\
Score 2 & $27,5^{\mathrm{b}}$ & $2,5^{\mathrm{a}}$ & $10^{\mathrm{ab}}$ & $7,5^{\mathrm{ab}}$ \\
Score 3 & $95^{\mathrm{c}}$ & $52,5^{\mathrm{b}}$ & $45^{\mathrm{ab}}$ & $20^{\mathrm{a}}$ \\
\hline
\end{tabular}

Means with different letters means significance by qui-square Test $(P<0.05)$

mainly the less abundant organisms. This finding was further evidenced by dendrograms that demonstrated the similarity of the microbiota membership of animals receiving $\mathrm{ZnO}$ (Fig. 4). The strong impact of $\mathrm{ZnO}$ on the cecal microbiota of pigs was confirmed by the statistical analysis (AMOVA and Parsimony) comparing beta diversity between the experimental groups (Table 4).

\section{Discussion}

As expected, animals supplemented with feed additives had better performance compared to controls, which might be related with intestinal health (lower rates and severity of diarrhea) and to the improved digestibility of nutrients $[27,28]$.

Zinc oxide aids to preserve intestinal mucosa integrity, modulating the immune system and protecting it against pathogenic bacteria [12]. Higher concentrations of $\mathrm{ZnO}$ have been associated with greater weight gain [17]. In the present study, the use of $\mathrm{ZnO}$ had a strong impact on the microbiota composition of the studied piglets as revealed by community analysis and reduced richness. Many studies have reported changes in intestinal bacteria of pigs 


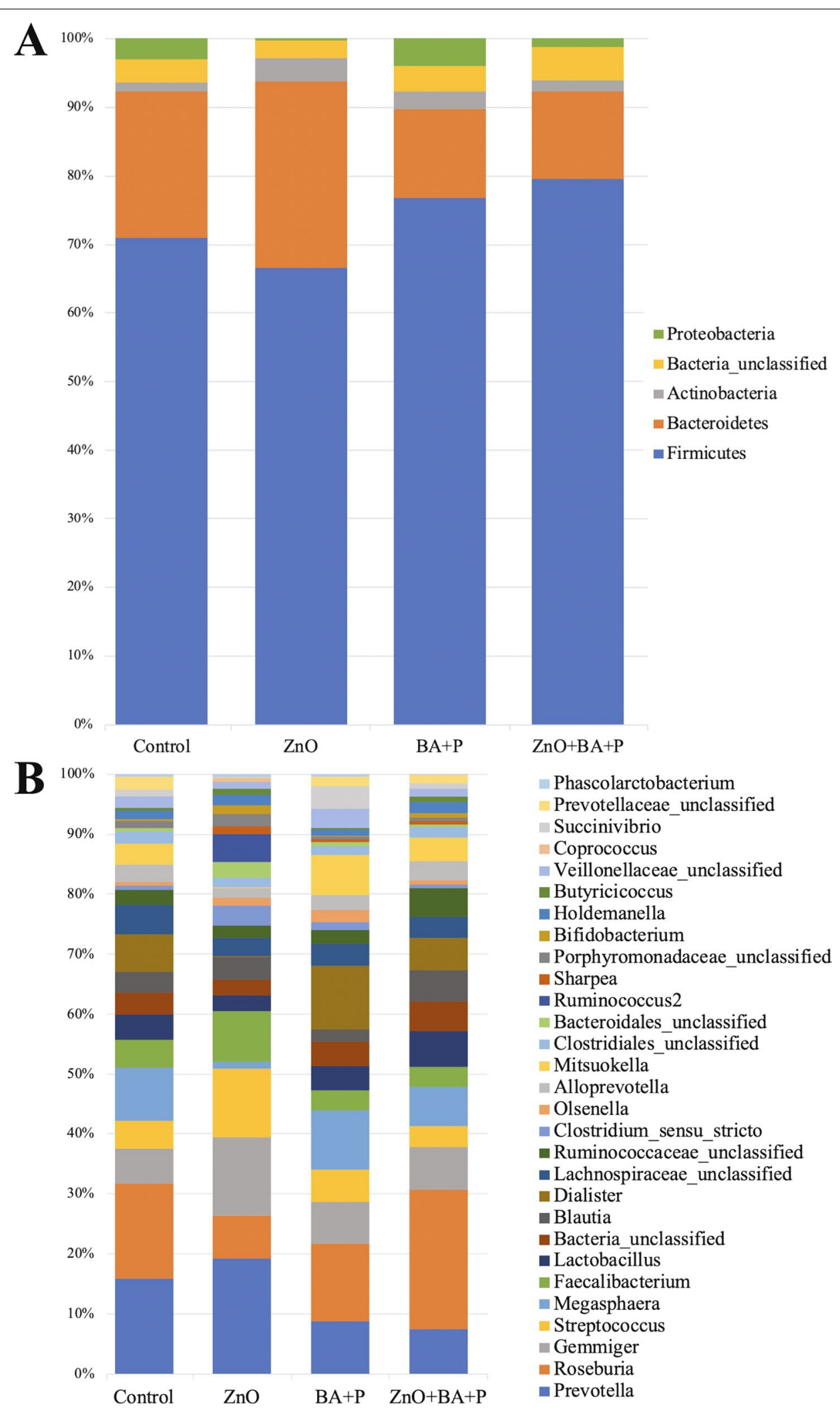

Fig. 1 Relative abundance of the main bacteria found in the swine cecum. Relative abundance of the phyla (A) and genera (B) with $>1 \%$ of abundance present in the cecal microbiota of piglets supplemented with Zinc Oxide ( $\mathrm{ZnO})$, Benzoic acid plus probiotics $(\mathrm{BA}+\mathrm{P}) ; \mathrm{ZnO}+\mathrm{BA}+\mathrm{P}$, and without supplementation (Control) 
Table 3 -values of the statistical analysis comparing alpha diversity indicators between treatments and controls

\begin{tabular}{lccc}
\hline Groups & Number of Genera & Chao & Simpson \\
\hline Control vs. ZnO & $0.0026^{*}$ & $0.0132^{*}$ & 0.6143 \\
Control vs. Benzoic acid + probiotic & $>0.9999$ & $>0.9999$ & $>0.9999$ \\
Control vs. ZnO+ Benzoic acid + probiotic & $0.0021^{*}$ & $0.0026^{*}$ & 0.2591 \\
ZnO vs. Benzoic acid + probiotic & $0.0054^{*}$ & $0.0077^{*}$ & $>0.9999$ \\
ZnO vs. ZnO+ Benzoic acid + probiotic & $>0.9999$ & $>0.9999$ & $>0.9999$ \\
Benzoic acid + probiotic vs. ZnO+ Benzoic acid + probiotic & $0.0043^{*}$ & $0.0015^{*}$ & $>0.9999$ \\
\hline
\end{tabular}

${ }^{*} P \leq 0.05$
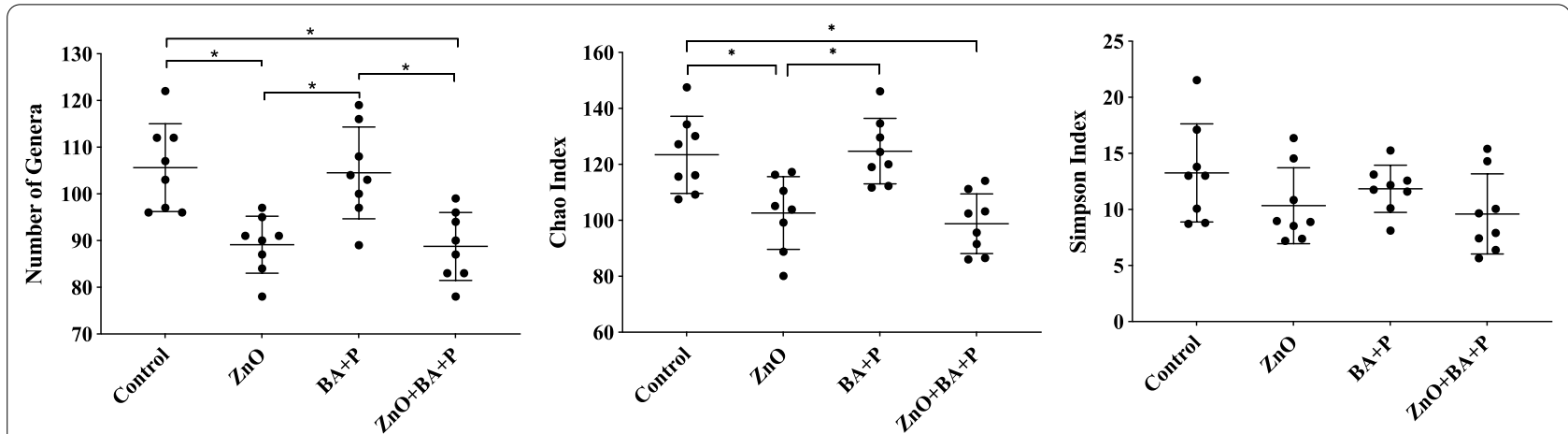

Fig. 2 Alpha diversity indices. Number of observed OTUs (A), Chao index (B) and Simpson's index (C) observed in the cecum of piglets post-weaning supplemented with Zinc Oxide $(\mathrm{ZnO})$, Benzoic acid plus probiotic (BA+P), ZnO + BA $+\mathrm{P}$, and no supplementation $\left(\right.$ Control). ${ }^{*} P \leq 0.05$

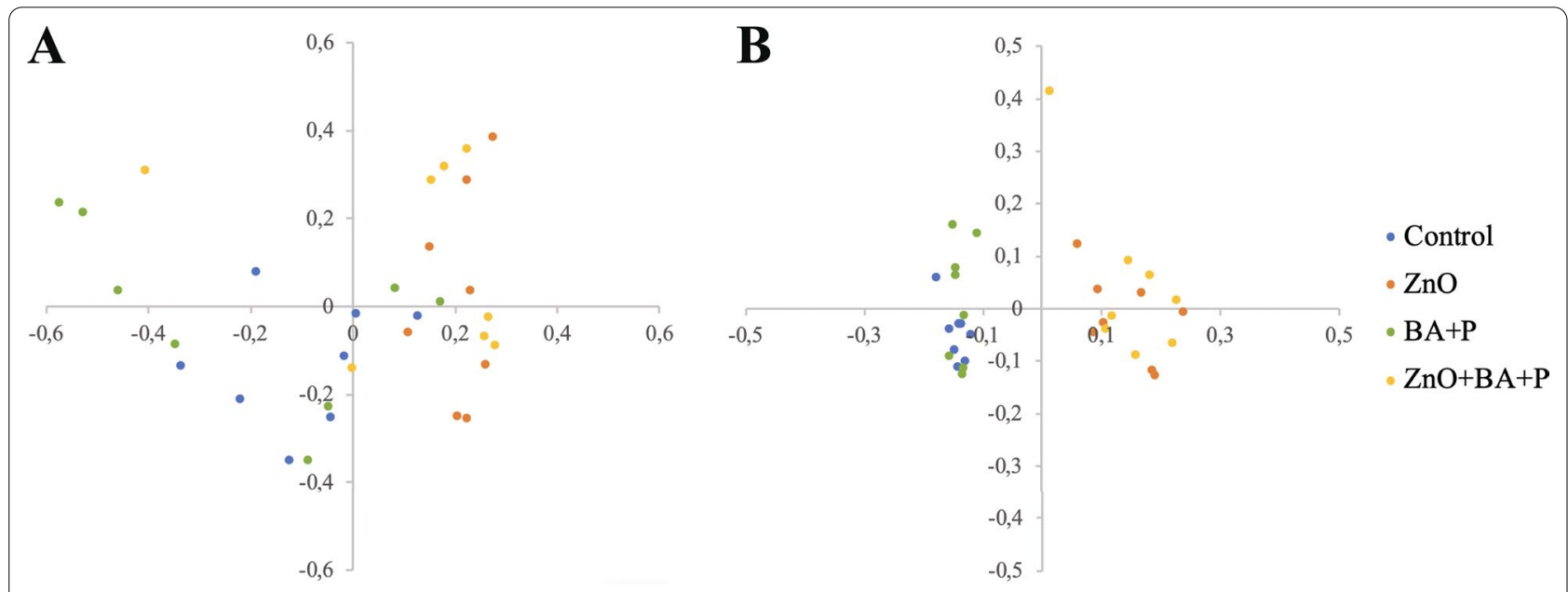

Fig. 3 Principal coordinate analysis (PCOA). PCoA comparing the similarities between bacterial community structure (A) and membership (B) present in the cecum of post-weaning piglets supplemented with Zinc Oxide ( $\mathrm{ZnO})$, Benzoic acid plus probiotic ( $\mathrm{BA}+\mathrm{P}), \mathrm{ZnO}+\mathrm{BA}+\mathrm{P}$, and without supplementation (Control)

caused by $\mathrm{ZnO}[29,30]$. The mechanisms by which $\mathrm{ZnO}$ improves growth performance are not completely understood, but it might increase the intestinal absorpiteve capacity by increasing the villus height [31].

Non-dissociated benzoic acid passes through the cellular membrane of bacteria releasing protons that acidify the medium [32], changing the bacterial metabolism and suppressing essential enzymes, such as decarboxylases and catalases [33, 34] Furthermore, benzoic acid improves the structure of the intestinal mucosa, reducing the crypt depth and increasing the villus/crypt ratio 


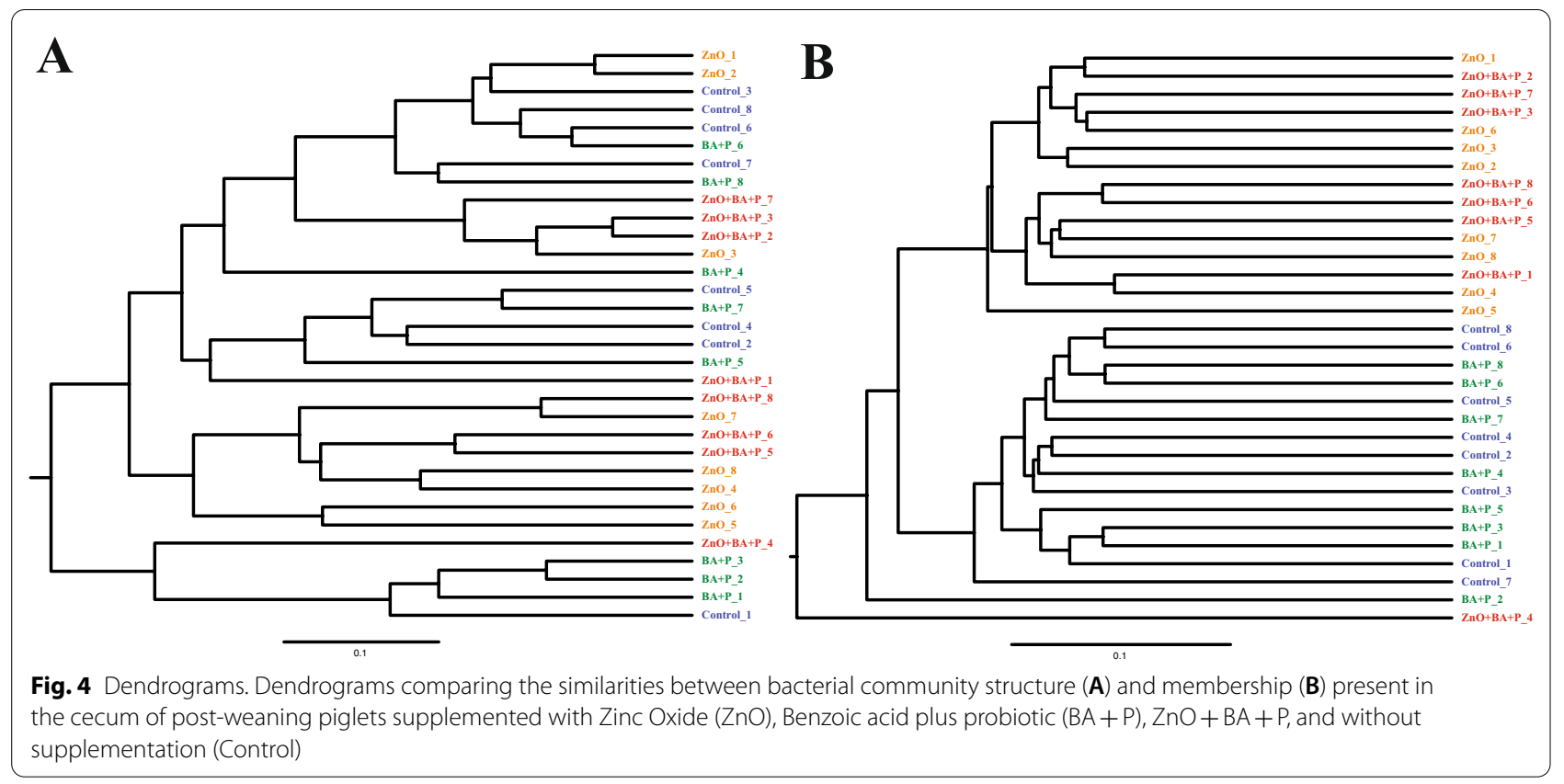

Table 4 P-values obtained by statistical analysis (AMOVA and Parsimony tests) comparing the similarity between bacterial communities in post-weaning piglets supplemented with $\mathrm{ZnO}$ and/or benzoic acid

\begin{tabular}{|c|c|c|c|c|}
\hline \multirow[t]{2}{*}{ Grupos } & \multicolumn{2}{|c|}{ Structure } & \multicolumn{2}{|c|}{ Membership } \\
\hline & AMOVA & Parsimony & AMOVA & Parsimony \\
\hline Control vs. ZnO & $0.001^{*}$ & 0.220 & $0.008^{*}$ & $<0.001^{*}$ \\
\hline Control vs. Benzoic acid + probiotic & 0.452 & 0.965 & 0.975 & 0.388 \\
\hline Control vs. $\mathrm{ZnO}+$ Benzoic acid + probiotic & $0.009^{*}$ & 0.199 & $0.005^{*}$ & $<0.001^{*}$ \\
\hline ZnO vs. Benzoic acid + probiotic & $0.003^{*}$ & 0.213 & $0.007^{*}$ & $0.001^{*}$ \\
\hline ZnO vs. $\mathrm{ZnO}+$ Benzoic acid + probiotic & 0.452 & 0.787 & 1.000 & 0.270 \\
\hline $\begin{array}{l}\text { Benzoic acid + probiotic vs. ZnO + Benzoic acid + probi- } \\
\text { otic }\end{array}$ & $0.012^{*}$ & 0.532 & 0.059 & $0.001^{*}$ \\
\hline
\end{tabular}

${ }^{*} P \leq 0.05$

culminating in improved digestibility and performance [35-37].

Probiotic organisms (i.e. Bacillus cereus, E. faecium, Saccharomyces cerevisae boulardii) can improve intestinal absorption and increase the transport of L-glutamine and ion secretion in piglets, preserving the mucosa integrity by reducing enterocyte mortality and improving protein digestibility [21, 37, 38]. Bacillus and Enterococcus are among the most used probiotics because of their potential to depleat pathogenens from the digestive tract and benefit commensal bacteria, controlling for diarrhea and improving performance $[21,39,40]$. The use of a specific strain of Ligilactobacillus salivarius was associated with increased clostridia and lactobacilli species as well as greater production of volatile fatty acids [19]. The use of symbiotics (a combination of probiotics with prebiotics) have also been shown to benefit fibrolytic bacteria, improving performancing and reducing inflammation in pigls [18].

Firmicutes and Bacteroidetes were the two major phyla found in the cecum of the studied piglets, which was in agreement with other studies [41-44]. Although not statistically significant, the abundance of Proteobacteria was higher in the groups not receiving $\mathrm{ZnO}$ (Fig. 1B). The inhibition of some Proteocateria species, such as Escherichia and Salmonella may have contributed to the lower rates of diarrhea and better performance observed in the present study [45-49]. Further studies using larger sample sizes are necessary to confirm this hypothesis. Specific taxa could not be associated to each of the treatment groups, likely because of interindividual variabilities in their relative abudances. The high abundance of Prevotella reported here can be explained by the increase in those organisms after weaning in piglets mainly related 
with the fibrolytic activity of the genus $[47,50,51]$. The genus Roseburia was also highly abundant in the intestinal tract of all studied piglets. These butyrate producing bacteria have been shown to be part of the normal microbiota of piglets [52] and belongs to the family Lachnospiraceae (Firmicutes), which is normally associated good intestinal health [53]. The genus Gemmiger is another Firmicutes of the Ruminococcaceae family that was highly abundant in this study. This bacterium seems to be favoured by the insertion of soybean meal in the diet of piglets [54], which might explain our results since this protein source was an important component of the diet used in the present study. The abundance of Megasphaera was numerically lower in the cecum of piglets receiving $\mathrm{ZnO}$ only, but the role of these commensal bacteria in the swine intestines deserves better attention [55].

Weaning is the most stressing event in swine production due to abrupt diet changes, displacement to new environments and housing with new individuals. Not surprisingly, this is the phase with the highest incidence of diarrhea and with the highest use of antibiotics [56]. The association of benzoic acid with probiotics and prebiotics has been suggested to have a synergic effect to favor weaned piglets' performance $[37,57,58]$, which are consistent with the present study. A recent study reported that supplementation of $\mathrm{ZnO}(1200 \mathrm{ppm})$ with a probiotic containing Bacillus coagulans, B. licheniformis, $B$. subtilis and $C$. butyricum had similar effect than higher doses of $\mathrm{ZnO}$ (3000 ppm) on many performance paramethers $[1,17]$.

Although the methods employed for this study are rather descriptive and not intended to prove a cause consequence relationship, it can be hypothesized that the microbiota changes induced by $\mathrm{ZnO}$ may play a role in weight gain by acting at different levels, such as modulating the local immunity, benefiting species that are more efficient in extracting energy from food or by competing with pathogenic organisms. Noteworthy, the beneficial effects of benzoic acid plus probiotic observed in the present study (i.e. on growth performance and diarrhea control) were similar to the ones obtained with the use of $\mathrm{ZnO}$ without inducing detectable changes in microbiota composition, avoiding the negative aspects of $\mathrm{ZnO}$ usage, such as development of resistance and environmental contamination.

\section{Conclusions}

The use of $\mathrm{ZnO}$ is associated with decreased richness and with changes in microbiota composition of weaning piglets. The use of Benzoic acid with probiotics yields similar performance results with lower impact on the gut microbiota compared to $\mathrm{ZnO}$, and it should be considered as a potential alternative in swine production.

\section{Abbreviations}

ZnO: Zinc oxide; BA: Benzoic acid; P: Probiotics; AGPs: Antibiotic growth promoters; NGS: Next generation sequencing; DFI: Daily feed intake; ADG: Average daily gain; FCR: Feed conversion rate; SD: Standard deviation; LEfSe: Linear discriminant analysis effective size; SRA: Sequence read archive; NCBI: National Center for Biotecnology Information; PCoA: Principal coordinate analysis; AMOVA: Analysis of molecular variance.

\section{Supplementary Information}

The online version contains supplementary material available at https://doi. org/10.1186/s42523-021-00151-y.

Additional file 1. Ingredients and calculated composition as-fed of the experimental diets of phases Pre-starter I and II (Table S1) and Starter I and II (Table S2).

\section{Acknowledgements}

Authors would like to thank Rebecca DiPietro for correcting the wirting of the manuscript.

\section{Authors' contributions}

CAS: Study design, interpretation of results, writing of manuscript. LATB: Data analysis, writing of manuscript. CPD: Experiment execution, data collection. MAC: Experiment execution, data collection. VBF: Study design, financial support. FTFD: Study design, financial support. AP: Study design, financial support, interpretation of results. CCSM: Study design, financial support, interpretation of results. MCC: Data analysis, interpretation of results, writing of manuscript. All authors read and approved the final manuscript.

Funding

This study was financed by DSM Nutritional Products and Akei Animal Research.

\section{Availability of data and materials}

Sequencing data is available at the Sequence Read Archive (SRA) - NCBI under the accession number PRJNA758076.

\section{Declarations}

Ethics approval and consent to participate

This study was carried out in accordance with the recommendations of the Guide for the Care and Use of Laboratory Animals of the National Animal Experimentation Control Council of Brazil (CONCEA). The trial was approved by the Ethics Committee of Animal Experiments of Akei Animal Research (protocol number: 005.2017).

\section{Consent for publication}

Not applicable.

\section{Competing interests}

CPD, MAC, FTFD, AP and CCSM work for Akei Animal Research. VBF works for DSM Nutritional Products.

\section{Author details}

${ }^{1}$ Department of Animal Science, Universidade Estadual de Londrina, Londrina, Paraná, Brazil. ${ }^{2}$ Department of Clinics, Surgery and Animal Reproduction, São Paulo State University (Unesp), Araçatuba, São Paulo, Brazil. ${ }^{3}$ Department of Veterinary Biomedical Sciences, Université de Montréal, Saint-Hyacinthe, Québec, Canada. ${ }^{4}$ Akei Animal Research, Fartura, São Paulo, Brazil. ${ }^{5}$ DSM Nutritional Products Ltd., Jaguaré, São Paulo, Brazil. 
Received: 16 September 2020 Accepted: 7 December 2021

Published online: 20 December 2021

\section{References}

1. Karasova D, Crhanova D, Babak V, Jerabek J, Brzobohaty L, Matesova Z, et al. Development of piglet gut microbiota at the time of weaning influences development of postweaning diarrhea-a field study. Res Vet Sci. 2021;135:59-65. https://doi.org/10.1016/J.RVSC.2020.12.022.

2. Silveira H, Amaral LG de M, Garbossa CAP, Rodrigues LM, Silva CC da, Cantarelli $V$ de $S$. Benzoic acid in nursery diets increases the performance from weaning to finishing by reducing diarrhoea and improving the intestinal morphology of piglets inoculated with Escherichia coli $\mathrm{K} 88^{+}$ J Anim Physiol Anim Nutr (Berl). 2018;102:1675-85. https://doi.org/10. 1111/jpn.12977.

3. Long L, Chen J, Zhang Y, Liang X, Ni H, Zhang B, et al. Comparison of porous and nano zinc oxide for replacing high-dose dietary regular zinc oxide in weaning piglets. PLoS ONE. 2017;12: e0182550. https://doi.org/ 10.1371/journal.pone.0182550.

4. Madec F, Bridoux N, Bounaix S, Cariolet R, Duval-Iflah Y, Hampson DJ, et al. Experimental models of porcine post-weaning colibacillosis and their relationship to post-weaning diarrhoea and digestive disorders as encountered in the field. Vet Microbiol. 2000;72:295-310. http://www. ncbi.nlm.nih.gov/pubmed/10727839. Accessed 11 Feb 2019.

5. Laine TM, Lyytikäinen T, Yliaho M, Anttila M. Risk factors for post-weaning diarrhoea on piglet producing farms in Finland. Acta Vet Scand. 2008;50:21. https://doi.org/10.1186/1751-0147-50-21.

6. Guevarra RB, Lee JH, Lee SH, Seok M-J, Kim DW, Kang BN, et al. Piglet gut microbial shifts early in life: causes and effects. J Anim Sci Biotechnol. 2019:10:1. https://doi.org/10.1186/s40104-018-0308-3.

7. Chen JL, Zheng P, Zhang C, Yu B, He J, Yu J, et al. Benzoic acid beneficially affects growth performance of weaned pigs which was associated with changes in gut bacterial populations, morphology indices and growth factor gene expression. J Anim Physiol Anim Nutr (Berl). 2017;101:113746. https://doi.org/10.1111/jpn.12627.

8. Campbell JM, Crenshaw JD, Polo J. The biological stress of early weaned piglets. J Anim Sci Biotechnol. 2013;4:19. https://doi.org/10.1186/ 2049-1891-4-19.

9. Hu C, Song J, Li Y, Luan Z, Zhu K. Diosmectite-Zinc oxide composite improves intestinal barrier function, modulates expression of pro-inflammatory cytokines and tight junction protein in early weaned pigs. $\mathrm{Br} J$ Nutr. 2013;110:681-8. https://doi.org/10.1017/S0007114512005508.

10. Kim JC, Hansen CF, Mullan BP, Pluske JR. Nutrition and pathology of weaner pigs: nutritional strategies to support barrier function in the gastrointestinal tract. Anim Feed Sci Technol. 2012;173:3-16. https://doi. org/10.1016/J.ANIFEEDSCI.2011.12.022.

11. Liu P, Pieper R, Rieger J, Vahjen W, Davin R, Plendl J, et al. Effect of dietary zinc oxide on morphological characteristics, mucin composition and gene expression in the colon of weaned piglets. PLOS ONE. 2014;9: e91091. https://doi.org/10.1371/journal.pone.0091091.

12. Pu J, Chen D, Tian G, He J, Zheng P, Mao X, et al. Protective effects of benzoic acid, Bacillus coagulans, and oregano oil on intestinal injury caused by enterotoxigenic Escherichia coli in weaned piglets. Biomed Res Int. 2018;2018:1-12. https://doi.org/10.1155/2018/1829632

13. Vahjen W, Pieper R, Zentek J. Increased dietary zinc oxide changes the bacterial core and enterobacterial composition in the ileum of piglets. J Anim Sci. 2011;89:2430-9.

14. Feng Z, Zhu H, Deng Q, He Y, Li J, Yin J, et al. Environmental pollution induced by heavy metal(loid)s from pig farming. Environ Earth Sci. 2018;77:103. https://doi.org/10.1007/s12665-018-7300-2.

15. Kim HB, Borewicz K, White BA, Singer RS, Sreevatsan S, Tu ZJ, et al. Longitudinal investigation of the age-related bacterial diversity in the feces of commercial pigs. Vet Microbiol. 2011;153:124-33.

16. Pluske JR, Turpin DL, Kim JC. Gastrointestinal tract (gut) health in the young pig. Animal Nutrition. 2018;4:187-96.

17. Huan W, Kun PK, In HK. Evaluation of the combined effects of different dose levels of Zinc oxide with probiotics complex supplementation on the growth performance, nutrient digestibility, faecal microbiota, noxious gas emissions and faecal score of weaning pigs. J Anim Physiol Anim Nutr (Berl). 2021;105:286-93. https://doi.org/10.1111/JPN.13493.
18. Hyun MC, Gemma G-O, Diego M-D, Jung MH, Gustavo C, Michael RB, et al. Stimbiotic supplementation improved performance and reduced inflammatory response via stimulating fiber fermenting microbiome in weaner pigs housed in a poor sanitary environment and fed an antibiotic-free low zinc oxide diet. PLoS ONE. 2020. https://doi.org/10. 1371/JOURNAL.PONE.0240264.

19. Sobrino OJ, Alba C, Arroyo R, Pérez I, Sariego L, Delgado S, et al. Replacement of Metaphylactic Antimicrobial Therapy by Oral Administration of Ligilactobacillus salivarius MP100 in a Pig Farm. Front Vet Sci. 2021;8: 666887. https://doi.org/10.3389/FVETS.2021.666887.

20. Starke IC, Pieper R, Neumann K, Zentek J, Vahjen W. The impact of high dietary zinc oxide on the development of the intestinal microbiota in weaned piglets. FEMS Microbiol Ecol. 2014;87:416-27.

21. Liu X, Xia B, He T, Li D, Su JH, Guo L, et al. Oral administration of a select mixture of lactobacillus and Bacillus alleviates inflammation and maintains mucosal barrier integrity in the ileum of pigs challenged with Salmonella infantis. Microorganisms. 2019;7(5):135. https://doi.org/10. 3390/microorganisms7050135.

22. Xiao D, Wang Y, Liu G, He J, Qiu W, Hu X, et al. Effects of chitosan on intestinal inflammation in weaned pigs challenged by enterotoxigenic Escherichia coli. PLoS ONE. 2014;9: e104192. https://doi.org/10.1371/ JOURNAL.PONE.0104192.

23. Schloss PD, Westcott SL, Ryabin T, Hall JR, Hartmann M, Hollister $E B$, et al. Introducing mothur: open-source, platform-independent, community-supported software for describing and comparing microbial communities. Appl Environ Microbiol. 2009;75:7537-41. https:// doi.org/10.1128/AEM.01541-09.

24. Kozich JJ, Westcott SL, Baxter NT, Highlander SK, Schloss PD. Development of a dual-index sequencing strategy and curation pipeline for analyzing amplicon sequence data on the miseq illumina sequencing platform. Appl Environ Microbiol. 2013;79:5112-20.

25. Cole JR, Wang Q, Fish JA, Chai B, McGarrell DM, Sun Y, et al. Ribosomal Database Project: Data and tools for high throughput rRNA analysis. Nucleic Acids Res. 2014;42(Database issue):D633-42. https://doi.org/ 10.1093/nar/gkt1244.

26. Segata N, Izard J, Waldron L, Gevers D, Miropolsky L, Garrett WS, et al. Metagenomic biomarker discovery and explanation. Genome Biol. 2011;12(6):R60. https://doi.org/10.1186/gb-2011-12-6-r60.

27. Diao $H$, Zheng P, Yu B, He J, Mao XB, Yu J, et al. Effects of benzoic acid on growth performance, serum biochemical parameters, nutrient digestibility and digestive enzymes activities of jejuna digesta in weaner piglets. Chin J Anim Nutr. 2013;25:768-77.

28. Torrallardona D, Badiola I, Broz J. Effects of benzoic acid on performance and ecology of gastrointestinal microbiota in weanling piglets. Livest Sci. 2007;108:210-3.

29. Jensen-Waern M, Melin L, Lindberg R, Johannisson A, Petersson L, Wallgren P. Dietary zinc oxide in weaned pigs - Effects on performance, tissue concentrations, morphology, neutrophil functions and faecal microflora. Res Vet Sci. 1998;64:225-31.

30. Shen J, Chen Y, Wang Z, Zhou A, He M, Mao L, et al. Coated zinc oxide improves intestinal immunity function and regulates microbiota composition in weaned piglets. Br J Nutr. 2014;111:2123-34. https:// doi.org/10.1017/S0007114514000300.

31. Sy Y, Sj S, Es C, Hs K, Jw C, Js K. Effects of zinc oxide and arginine on the intestinal microbiota and immune status of weaned pigs subjected to high ambient temperature. Anim an open access J from MDPI. 2020;10:1-15. https://doi.org/10.3390/ANI10091537.

32. Kluge $\mathrm{H}, \mathrm{Broz} \mathrm{J}$, Eder K. Effect of benzoic acid on growth performance, nutrient digestibility, nitrogen balance, gastrointestinal microflora and parameters of microbial metabolism in piglets. J Anim Physiol Anim Nutr (Berl). 2006;90:316-24. https://doi.org/10.1111/j.1439-0396.2005. 00604.x.

33. Chiquieri J, Soares RTRN LMHV e F, JB. Ácidos orgânicos na alimentação de leitões desmamados. Arch Zootec. 2009;v.58:p.609-612.

34. Gauthier R. The mode of action of acidifiers and the interest they generate in the growingfinishing phase. In: Current Developments in Pig Production, French Association of Swine Practitioners. French Assoc Swine Pract. 2002;Maisons-Al France:16.

35. Bi Y, Cox MS, Zhang F, Suen G, Zhang N, Tu Y, et al. Feeding modes shape the acquisition and structure of the initial gut microbiota in 
newborn lambs. Environ Microbiol. 2019;21:2333-46. https://doi.org/ 10.1111/1462-2920.14614.

36. Consortium THMP, Huttenhower C, Gevers D, Knight R, Abubucker S, Badger $\mathrm{JH}$, et al. Structure, function and diversity of the healthy human microbiome. Nature. 2012;486:207-14. https://doi.org/10.1038/natur e11234.

37. Oliveira NTE, Carvalho PLO, Genova JL, Cristofori EC, Silveira FHR, Junior OAC. Addition of different probiotics to commercial feeds for piglets during the nursery phase. Semin Agrar. 2019:40:1225-36. https://doi. org/10.5433/1679-0359.2019v40n3p1225.

38. Lodemann U, Lorenz BM, Weyrauch KD, Martens H. Effects of Bacillus cereus var. toyoi as probiotic feed supplement on intestinal transport and barrier function in piglets. Arch Anim Nutr. 2008;62:87-106.

39. Kozasa M. Toyocerin (Bacillus toyoi) as growth promotor for animal feeding. Microbiol Aliment Nutr. 1986:4:121-35.

40. Whittemore C. Optimisation of feed supply to growing pigs and breeding sows. In: Whittemore's Science and Practice of Pig Production. Oxford, UK: Blackwell Publishing Ltd; 2007. p. 472-506. https://doi.org/10.1002/97804 70995624.ch15.

41. Jami E, Mizrahi I. Composition and similarity of bovine rumen microbiota across individual animals. PLoS ONE. 2012;7: e33306. https://doi.org/10. 1371/journal.pone.0033306.

42. O' Donnell MM, Harris HMB, Ross RP, O'Toole PW. Core fecal microbiota of domesticated herbivorous ruminant, hindgut fermenters, and monogastric animals. Microbiologyopen. 2017;6:e00509. https://doi.org/10.1002/ mbo3.509.

43. Dougal K, de la Fuente G, Harris PA, Girdwood SE, Pinloche E, Geor RJ, et al. Characterisation of the faecal bacterial community in adult and elderly horses fed a high fibre, high oil or high starch diet using 454 pyrosequencing. PLoS ONE. 2014;9: e87424. https://doi.org/10.1371/ journal.pone.0087424.

44. Wang J, Fan H, Han Y, Zhao J, Zhou Z. Characterization of the microbial communities along the gastrointestinal tract of sheep by 454 pyrosequencing analysis. Asian-Australasian J Anim Sci. 2017;30:100-10. https:// doi.org/10.5713/ajas.16.0166.

45. Hu J, Nie Y, Chen J, Zhang Y, Wang Z, Fan Q, et al. Gradual changes of gut microbiota in weaned miniature piglets. Front Microbiol. 2016;7:1727. https://doi.org/10.3389/fmicb.2016.01727.

46. Niu Q, Li P, Hao S, Zhang Y, Kim SW, Li H, et al. Dynamic distribution of the gut microbiota and the relationship with apparent crude fiber digestibility and growth stages in pigs. Sci Rep. 2015;5:9938. https://doi.org/10. 1038/srep09938.

47. Pajarillo EAB, Chae JP, Balolong MP, Kim HB, Kang DK. Assessment of fecal bacterial diversity among healthy piglets during the weaning transition. J Gen Appl Microbiol. 2011;60:140-6.

48. Li T, Liu Z-H, Li K, Bai H-H. Evaluation of the vaginal microbiome in clinical diagnosis and management of vaginal infectious diseases. Chin Med J (Engl). 2019. https://doi.org/10.1097/CM9.0000000000000211.

49. Wang W, Van Noten N, Degroote J, Romeo A, Vermeir P, Michiels J. Effect of zinc oxide sources and dosages on gut microbiota and integrity of weaned piglets. J Anim Physiol Anim Nutr (Berl). 2019;103:231-41. https://doi.org/10.1111/jpn.12999.

50. Xie Z, Hu L, Li Y, Geng S, Cheng S, Fu X, et al. Changes of gut microbiota structure and morphology in weaned piglets treated with fresh fermented soybean meal. World J Microbiol Biotechnol. 2017;33(12):213. https://doi.org/10.1007/s11274-017-2374-7.

51. Motta V, Luise D, Bosi P, Trevisi P. Faecal microbiota shift during weaning transition in piglets and evaluation of AO blood types as shaping factor for the bacterial community profile. PLoS ONE. 2019;14: e0217001. https://doi.org/10.1371/journal.pone.0217001.

52. Md. Abul KA, Qiankun G, Cui M, Kai W, Xiangfeng K. Betaine hydrochloride addition in Bama mini-pig's diets during gestation and lactation enhances immunity and alters intestine microbiota of suckling piglets. Sci Food Agric. 2021. https://doi.org/10.1002/JSFA.11389.

53. Zohreh T-S, Imen S, Latifa B, Olivier L, Vincent M, Shao BF, et al. Roseburia spp.: a marker of health? Future Microbiol. 2017;12:157-70. https://doi. org/10.2217/FMB-2016-0130.

54. Li R, Chang L, Hou G, Song Z, Fan Z, He X, et al. Colonic microbiota and metabolites response to different dietary protein sources in a piglet model. Front Nutr. 2019;6:151. https://doi.org/10.3389/FNUT.2019.00151.
55. Grosu IA, Pistol GC, Marin DE, Cişmileanu A, Palade LM, Ţăranu I. Effects of dietary grape seed meal bioactive compounds on the colonic microbiota of weaned piglets with dextran sodium sulfate-induced colitis used as an inflammatory model. Front Vet Sci. 2020;7:31.

56. Gresse R, Chaucheyras-Durand F, Fleury MA, Van de Wiele T, Forano E, Blanquet-Diot S. Gut microbiota dysbiosis in postweaning piglets: understanding the keys to health. Trends Microbiol. 2017;25:851-73.

57. Papatsiros VG, Tassis PD, Tzika ED, Papaioannou DS, Petridou E, Alexopoulos $C$, et al. Effect of benzoic acid and combination of benzoic acid with a probiotic containing Bacillus cereus var. Toyoi in weaned pig nutrition. Pol J Vet Sci. 2011;14:117-25.

58. Zhang ZF, Rolando AV, Kim IH. Effects of benzoic acid, essential oils and Enterococcus faecium SF68 on growth performance, nutrient digestibility, blood profiles, faecal microbiota and faecal noxious gas emission in weanling pigs. J Appl Anim Res. 2016;44:173-9. https://doi.org/10.1080/ 09712119.2015.1031765.

\section{Publisher's Note}

Springer Nature remains neutral with regard to jurisdictional claims in published maps and institutional affiliations.

Ready to submit your research? Choose BMC and benefit from:

- fast, convenient online submission

- thorough peer review by experienced researchers in your field

- rapid publication on acceptance

- support for research data, including large and complex data types

- gold Open Access which fosters wider collaboration and increased citations

- maximum visibility for your research: over $100 \mathrm{M}$ website views per year

At BMC, research is always in progress.

Learn more biomedcentral.com/submissions 